\title{
Aspirations and Social Mobility: the role of social and spatial (im)mobilities in the development and achievement of young people's aspirations
}

\author{
Sonja Marzi, \\ University of East Anglia, \\ School International Development \\ Email: Sonja.marzi@me.com
}

\begin{abstract}
This chapter illustrates the importance of young people's spatial (im)mobility in facilitating upward social mobility in relation to their aspirations and provides conceptual resources for research with young people from a development studies and human geography perspective. Research on aspirations for upward social mobility, with a particular focus on educational and occupational aspirations, often draws on the neo-liberal discourse, shifting the achievement of upward social mobility through the development of higher aspirations towards young people's individual responsibility (Allen and Hollingworth, 2013). Despite this, high aspirations alone are not sufficient drivers of upward social mobility as young people are embedded in their social and cultural contexts and enabled or constrained by their socio-economic conditions. This chapter briefly discusses the concept of social mobility and its drivers - such as the acquisition of social and cultural capital (Reynolds, 2013) and being supported to develop the 'right' habitus to move socially upwards. It draws attention to the importance of physical mobilities and in particular neighbourhoods are discussed as crucial places where the acquisition of capitals, development of habitus and skills necessary for social mobility are developed. The relationship between spatial and social mobility is illustrated through examples from the global north and south demonstrating how spatial (im)mobility affects young people's experiences in ways that determine the future choices they perceive as possible and available to them (Winton, 2005). Thus research on young people's social mobility requires an inclusion of the spatial dimension of mobilities to understand how young people navigate themselves towards their aspirations.
\end{abstract}




\section{Introduction}

In recent research in a range of disciplines such as anthropology, development studies, geography, education, cultural studies and youth studies, the topic of aspirations and raising aspirations, in the sense of setting future goals, to achieve upward social mobility has been of emergent interest. A definition of social mobility explains the concept as people's upward and downward movement in society with respect to status or class position in relation to others within the same society's hierarchy (Azevedo and Bouiilon, 2010; Gough, 2008). Aspirations have been defined in terms such as hopes for future life, goals, wants or future desires, suggesting there is not one agreed meaning of the term (Brown, 2011; Ibrahim, 2011; Prince, 2013). Ibrahim (2011: 3) defines aspirations as 'hopes or ambitions to achieve something', based on research in Egypt. Ray (2006) develops the notion of an aspiration gap - the distance between the aspirations and the actual condition. It is this gap that affects future-oriented behaviour. If the gap is too wide the aspirations are perceived as too distant to be reached and if it is too narrow they are perceived as too small to be worth investing in. Studying young people's aspirations provides insights into how they experience their present life and what is their desired future, while simultaneously obtaining knowledge about their behaviour to achieve these (Crivello, 2011). While the majority of research on young people's aspirations has focused on educational and occupational aspirations (Brown, 2011; Kintrea, St Clair, \& Houston, 2015) they go beyond education and occupation by including, for example, material and personal aspects such as home ownership and family life.

With a particular focus on policies about young people's educational and occupational aspirations, especially in the UK and Australia and in regard to youth from disadvantaged socioeconomic backgrounds, the rationale behind raising aspirations is for young people to aim for higher education and related employment opportunities and thus move upwards in the society's hierarchy (cf. Allen and Hollingworth, 2013; Gale and Parker, 2015; Holloway and Pimlott-Wilson, 2011). Still, while the discourse of raising aspirations and their related policies intend to raise higher education attainment, and provide young people with the skills to be part of the knowledge economy, to increase employability and consequently enhance social mobility, Brown (2011) asserts that these policies go beyond this with focusing on aspirations that lead to the development of a self-reliant citizen. He posits that a neo-liberal, post-welfare discourse of raising aspirations understands being aspirational as a means to position young people and their individual responsibility to invest in the future according to policy goals and thus to develop future self-reliant citizens (Brown, 2011: 13-14). This creates a shift, placing the responsibility for achieving upward social mobility and being successful adults in the future, 
on to young people themselves, promoting social mobility as an individualised obligation (Brown, 2013; Spohrer, 2011). In this sense, a lack of aspirations is perceived as the reason for low educational and occupational achievements that in turn results in low or even in downward social mobility.

However, aspirations are not developed and achieved independently of one's social context. Creating a discourse where social mobility is dependent on one's individual capacities to achieve educational and occupational success ignores the spatial and structural influences emerging from young people's social context. These influences may restrict them in being exemplars of this aspirations-upward mobility discourse. Thus while aspirations are perceived as an important driver to achieve upward social mobility, aspirations alone are not sufficient to achieve upward mobility.

Taking another approach, Appadurai (2004) understands aspirations as a cultural and navigational capacity, embedded in the cultural, social and political context with its norms, behaviours and beliefs. He develops the concept of the 'capacity to aspire' that refers to the capacity to develop both aspirations as well as strategies to attain them, the ability to navigate towards one's aspirations. He argues that the capacity to aspire is much dependent on the routes and networks experienced in the past and projected into the future. Routes and networks refer to the experiences and knowledge one receives when moving through past and present spaces and places, such as experiences young people gain through moving through their neighbourhood and beyond on a daily basis. And while education has been identified as one of the main drivers for upward social mobility, young people need to acquire social and cultural capital to navigate successfully towards upward social and economic mobility (Gough, 2008; Kintrea, St Clair, \& Houston, 2015). These physical movements then shape the young people's habitus, determining the thinking and acting of a person, and their mobilities provide them with possibilities to acquire capitals necessary for navigating them towards their aspirations (Kintrea, St Clair, \& Houston, 2015). Places and spaces, and in particular the neighbourhood and immediate social surroundings, are factors that influence young people's opportunities to acquire these capitals and thus the alteration of their social condition (Reynolds, 2013). Therefore young people's everyday spatial mobilities are significant influences on their social mobility and aspirations achievements. They develop a navigational capacity that enables them, with acquisition of necessary capitals and skills, to react and adjust to constraints and possibilities within their places and spaces (Kintrea, St Clair, \& Houston, 2015; Langevang and Gough, 2009; Vigh, 2006).

This chapter focuses on young people's mobilities within their neighbourhoods and important places in relation to them. It illustrates with examples from the global north and south how young people 'move' in their everyday lives in order to acquire the resources necessary to navigate towards their 
aspirations for social mobility while simultaneously being required to adjust to changes in their social environment. The chapter demonstrates how young people's mobilities as well as immobilities, understood as a social resource itself, are influenced by their everyday spaces and places, an important factor that needs to be included when examining young people's aspirations. One crucial aspect is the neighbourhood young people live in and how neighbourhoods influence habitus and capital acquisition. They provide opportunity structures for social mobility that enable or constrain young people to move socially and economically. Accordingly as much as mobility is perceived as a social resource, immobility, as the absence of it, creates constraints and difficulties to acquire the necessary resources to achieve upward social mobility and be aspirational. Their social mobility is rather interrelated with young people's social contexts including neighbourhood influences and the opportunities they provide to develop and attain resources. Therefore there is a need to examine young people's physical mobilities within their neighbourhood and beyond in order to understand the different influences that enable or constrain young people's social mobility and to explore how to assist young people in the attainment of their aspirations.

The first part of this chapter starts with a short overview of social mobility and how young people's spatial and social mobility enable or constrain their access to resource to enhance their social conditions and achieving their aspirations. The second part of the chapter provides a brief overview of the literature on neighbourhood effects and explores young people's (im)mobilities in and beyond their neighbourhoods to illustrate how these effects are interconnected with young people's aspirations' attainment. It illuminates in particular how young people's sense of belonging to neighbourhoods, geographical neighbourhood effects, as well as social-interactional effects impact on young people's (im)mobilities, with a focus on young people from lower socioeconomic backgrounds. The impact on young people's (im)mobilities is linked to their aspirations and the aspirations' upward social mobility discourse as they enable or constraint young people to acquire necessary skills and resources to attain their aspirations. Thus in the concluding section a connection will be created back to young people's aspirations and the discourse around them making social mobility an individualised responsibility where discourse ignores the unequal personal conditions when pursuing to attain aspirations. While much of the research related to mobilities and aspirations focuses on countries from the global north, the chapter focuses on examples from both the global north and south. 


\section{Mobility as a Resource to Attain Aspirations of Upward Social Mobility}

Gough (2008) describes social mobility as people's movements in society, looking at social movement upwards or downwards in terms of status or class position in relation to others within a society's hierarchy (Azevedo and Bouiilon, 2010). Azevedo and Buillon (2010) illustrate sociological and economic concepts of social mobility. From a sociological perspective social mobility is defined by indicators of movements between social classes, occupational groups and opportunities available for advancement; the economic perspective measures social mobility through earnings and income mobility. While the first concept of social mobility provides information about opportunity structures including power relations within them, the second is a measure of resources at a specific point of time (Azevedo and Bouiilon, 2010); both concepts are linked to each other as opportunity structures and concentration of means of power are often interrelated with economic resources available. Those with more economic resources are usually those who are provided with more opportunities and are part of the more powerful positions in the hierarchy of a society. However, while social mobility indeed is linked to an enhancement of an individual's position in a society's hierarchy and depends much on capital acquisitions, it is not limited to these. Similar to aspirations for social mobility, social mobility itself can be defined in terms other than status, wealth and money. Therefore being able to create a change towards living in a safer neighbourhood, starting a family, moving to a place where one feels comfortable and at ease may be perceived as social mobility as well and create aspirations towards these changes. For example, Perlman (2006: 161) describes in her study of people from favela neighbourhoods in Rio de Janeiro that the change of neighbourhood can shift the status of an individual in society through moving away from the stigma and danger in those favelas but reducing the individual's economic resources.

This chapter concentrates on the sociological approach to social mobility, thus the change in status and a society's hierarchy, acknowledging that economic resources are still an additional important factor. Bourdieu $(1989 ; 1977)$ argues that to be able to move between classes in a society's hierarchy, individuals need to acquire capitals and develop the habitus valued by the respective class. Habitus is a way of understanding how actions of individuals are developed and regulated and Bourdieu defines habitus as

'[...] a system of dispositions, that is of permanent manners of being, seeing, acting and thinking, or a system of long-lasting (rather than permanent) schemes or schemata or structures of perception, conception and action' (Bourdieu, 2005: 43). 
Therefore habitus is a set of subconscious, internalised structures that generate behaviour, beliefs, attitudes and tastes and determine how to think and act in certain ways that are appropriate to a person's social class. Capitals, on the other hand, are resources that enhance an individual's position within particular classes or social hierarchies. Bourdieu distinguishes economic capital, economic resources, from cultural and social capital. Social capital comprises networks and social connections; cultural capital refers to non-economic capitals valued by the field's habitus and covers a wide variety of resources including verbal facility, aesthetic preferences, information about school systems, social class attributes, and education (Bourdieu and Passeron, 1977). Both social and cultural capital can be converted into economic advantage and influence social mobility outcomes. In a study in Cali (Colombia), for instance, young people and adults mentioned that through their networks in their neighbourhood they experience support in form of financial resources when friends pay loans back or when borrowing money from others within the network (Asociación Arte y Cultura et al., 2002). In other cases social capital can lead to acquisition of economic capital through work opportunities that result out of membership to a network (Langevang and Gough, 2009).

Allen and Hollingworth (2013) argue that through the neo-liberal discourse of raising aspirations, young people from disadvantaged neighbourhoods have been labelled as suffering from low aspirations without acknowledging that aspirations are shaped by a place-based habitus and the amount and types of capitals acquired. Social class and place shape young people's aspirations and how young people perceive their spatial and social mobility opportunities depends much on their ability to acquire and convert social and cultural capital as well as the experiences young people gain through moving through places and spaces (Prince, 2013). Thus Allen and Hollingworth (2013) criticise the neo-liberal discourse as positioning aspirations as asocial and aspatial as well as disregarding that young people have unequal access to resources necessary to develop and realise aspirations that are perceived as the 'right' aspirations for achieving upward social mobility (Gale and Parker, 2015). This creates the question of where young people acquire the necessary capitals and experiences that influence their aspirations.

Aspirations and their attainment are not only the product of one's own abilities (as neo-liberal discourse argues) but of many factors such as opportunities, changing environments and supporting contacts through established networks. Consequently, the ability to develop the 'right' aspirations and navigate towards them successfully is not evenly distributed across societies and classes. Class or the position in society's hierarchy plays a crucial role in shaping possession of capitals to navigate successfully to upward social mobility. Although socioeconomic background and class are important 
influences, places and spaces as geographic locations are settings of resource acquisition. According to Bourdieu (1977) the acquisition of capital can alter the habitus and provide access to higher classes. The examples presented here suggest that physical mobilities in places and spaces enhance access to capitals and opportunities to form one's habitus. The physical place is then a setting and representation of social and economic forces and living in a place as well as being from a certain social background influences life chances of young people (Kintrea, St Clair, \& Houston, 2015; van Ham et al., 2012). This does not exclude that both have an influence; being from a place interrelates with the socioeconomic background, but it shifts the analytical focus to the neighbourhood and how disadvantaged neighbourhoods affect young people and their social mobility opportunities.

\subsection{Mobility and The Neighbourhood}

Wilson (1987), one of the first authors of the neighbourhood effects literature, argues that disadvantaged neighbourhoods create social isolation for the people living in them. He claims residents of disadvantaged neighbourhoods suffer from isolation from mainstream individuals and institutions, which subsequently results in a reduction of access to knowledge and resources in other parts of the city. The neighbourhood effects literature implies that an individual's life chances, opportunities, experiences and socialisation process are linked to the place of living (Musterd and Andersson, 2006; van Ham et al., 2012). It is interested in the reproduction of inequalities and the consequences experienced by people when belonging to certain neighbourhoods. One important aspect in this regard is people's mobilities within and beyond neighbourhoods to overcome this isolation from mainstream individuals and institutions and thus how people can use physical mobility as a resource to enhance life chances and attain upward social mobility.

Sheller and Urry (2006) illustrate within a new mobilities paradigm that spatial mobility affects social upward or downward mobility and moving physically or virtually can be converted into a source of status and power (Sheller and Urry, 2006: 213). In this regard, Kaufmann, Bergmann \& Joye (2004) understand mobility as an additional form of capital, a form of capital that can enhance access to economic, social and cultural capital, and thus social mobility. They developed the concept of motility that distinguishes the potential of an individual to move independently from the actual intention to move. Thus separating these two, the potential for movement includes, for instance, the knowledge about how to move, transportation available, physical availability to move and so on. Once an individual has the intention to move and actually moves motility converts into mobility (Cranzler et al., 2008: 3 cited in Skelton, 2013: 471). Yet, mobility is a resource not everyone has equal access to and 
immobility may lead to stagnated social mobility or even downward social mobility. Referring back to Appadurai and his notion of the capacity to aspire, in relation to young people's aspirations, that is created from past and present experiences (Appadurai, 2004), leads one to ask about the places and spaces young people move in and through in their everyday lives, to look rather at their routes than their roots (Massey, 1998) and understand how aspirations are influenced by mobilities of young people.

Being mobile is linked to place and specifically to the neighbourhood young people live in. Young people's movements in and beyond their neighbourhood are closely related to their social mobility outcomes, as their physical mobility influences their access to resources, which in turn enables them more likely to realise their aspiration of upward social mobility. However, those from more privileged neighbourhoods obtain more means to travel and have wider access to spaces and places, offering them more opportunities to access resources of different kinds. Therefore depending on which kind of neighbourhood young people live in, the neighbourhood generates positive effects resulting in greater physical and/or social mobility and thus more access to resources or it can generate negative effects that create spatial and social immobility. Aspirations are subsequently influenced and developed through the interrelation of these (im)mobilities, possible opportunities and capital acquisitions (see Musterd and Andersson, 2006: 120).

Especially socioeconomically disadvantaged neighbourhoods are perceived as having an influence on social mobility outcomes in terms of social-occupational immobility, and poorer quality educational opportunities because of limited quality in the provision of education, social exclusion and behavioural outcomes. Disadvantaged neighbourhoods reproduce inequalities generating social and spatial mobility restrictions on their residents' lives. This is particularly important for young people's navigational capacity to attain their aspirations, and thus their ability to plot from the present into the future and to act in relation to immediate constraints and possibilities (Langevang and Gough, 2009: 742).

According to recent literature on neighbourhood effects (Sharkey and Faber, 2014; van Ham et al., 2012) the amount of studies about those effects is growing providing information about how neighbourhoods negatively impact on individuals. After the 'Moving to Opportunity' study, a large quantitative neighbourhood effect study in different big cities in the US, many authors of the neighbourhood effects literature argue that it is not possible to answer the questions of whether and when neighbourhood effects matter; instead of asking whether they matter or not, the issue to be researched is under what conditions they matter, as they need to be understood as context specific 
(Sharkey and Faber, 2014; van Ham et al., 2012). This suggests that in addition to the large volume of quantitative studies, more qualitative research is needed to understand the causation and context of neighbourhood influences (Small and Feldman, 2012). There is no evidence that the neighbourhood people live in limits or enhances their life chances independently from other factors that intersect or contribute to people's social mobility such as ethnicity, class, education, gender, and studies should need to include this aspect when analysing neighbourhoods with their opportunity structures (van Ham et al., 2012). The mobilities literature that investigates links between individuals' spatial mobilities, place and social mobility partly answers this gap (Gough, 2008; Langevang and Gough, 2009; Skelton, 2013).

With respect to the interrelationship of young people's aspirations and place, Prince (2013) claims that the physical environment plays a crucial role in the development of young people's possible future selves. She claims that place-based experiences are internalised and converted to possible future selves including daily aspects of the physical environment. The internalisation of place is hence embodied into young people's habitus and this process of internalisation creates a place-identity, a sense of belonging and place-based behaviour (Prince, 2013). Accordingly Skelton (2013) argues that 'to move between places can provide the opportunities for social encounters that form part of the complex cultural and social matrix of identity formation', and physical mobility can enhance social mobility but also threaten it through encounters of confrontation, fear and danger (Skelton, 2013: 472).

Therefore neighbourhoods influence young people's physical and social mobility. That does not mean that more physical mobility necessarily results in enhanced social mobility and/or higher aspirations attainment; this has to be explored in specific contexts. Skelton and Gough (2013: 460), for example, argue that 'a focus on mobilities aids the analysis of networks and flows that link people and places' and while young people move through places to realise opportunities, whether they relate to material or social mobility, they are affected by place-based and social conditions. For example, in a study of young people in Zambia's capital Lusaka, Gough (2008) illustrates that physical mobility does not lead subsequently to social mobility and even when being physical mobile one can still be socially immobile. Through engaging in daily and residential mobility the young people of her study try to enhance their social mobility. They move on a daily basis searching for job opportunities or residentially for family and educational reasons; however opportunities to enhance their social mobility are scarce and thus even though moving physically they may stay socially immobile. Aspirations' attainment towards 
upward social mobility can be then constrained by the young people's circumstances and their social context.

In another study placed in the African continent, in Accra, Ghana, Langevang and Gough (2009) analyse young people's physical mobility for material and social survival and how everyday movement of young people influences their social mobility as well as their perceptions of their futures. Including young people's perspectives on the future in a challenging environment, they use a social navigation approach in their study based on Vigh's (2006) concept of social navigation.

'A theory of social navigation: that is, through attentiveness to the way in which agents seek to draw and actualise their life trajectories in order to increase their social possibilities and life chances in a shifting and volatile social environment (Vigh, 2006: $11)$.

Social navigation therefore is the agency of young people to develop movements from the present towards desired future selves with the ability to act and adjust their movement according to a changing social environment including its changing constraints and possibilities. Therefore they include an implicit aspirational perspective into their study asking about the young people's perspective on their future related to social context influences. Their findings illustrate that people who move frequently may do so involuntarily and still experience social immobility. Although young people in Accra moved constantly, physically from their neighbourhood to other important places in the city, in search of work and education opportunities and resources, they had to adjust to fast-changing opportunity structures (Langevang and Gough, 2009). The examples demonstrate that being successful depends on an interrelation of one's abilities, networks and opportunities and many young people experience social immobility, even though they try to enhance their chances through physical mobility every day.

The following sections present five chosen, and often interrelated, aspects of how neighbourhoods influence young people. While the five aspects of neighbourhood influences have been chosen resulting from the author's research, influences of neighbourhoods are not limited to these five chosen influences and may vary depending on the social context. The chosen aspects are: first, how neighbourhoods create a sense of belonging and influence young people's aspirations; second, and in relation to belonging, how living in a stigmatised neighbourhood has an impact on young people's mobilities and possible future selves; third, the influence of the geographical location of the neighbourhood within the city and in relation to other important locations(for example the distance to education facilities can be one of those factors); and fourth, the influence of the immediate 
neighbourhood, its infrastructure and social-interactional factors within it; and finally fifth, the influence of levels of insecurity in neighbourhoods and their impact on mobilities of young people and thus on their navigational capacity to achieve upwards social mobility.

Therefore, having demonstrated that for an analysis of young people's aspirations, it is necessary to look at young people's contextualised mobilities to investigate where and how they acquire necessary capitals and resources for spatial and social mobility, the next section will illustrate the influence of the neighbourhood in particular.

\subsection{Belonging to a neighbourhood}

Belonging and a sense of belonging is one of the major influences on young people's mobilities. Neighbourhood belonging is related to the geographical location of a neighbourhood, its composition in terms of ethnicity and socioeconomic background, related cultures and its networks that serve different purposes such as access to resources and security (Bourdieu, 1989; May, 2013; Reynolds, 2013).

A sense of belonging to place incorporates two main interrelated aspects, a place attachment giving meaning to a particular geographical place (Miller, 2003) and the relationships one has to people within these places (Cuervo and Wyn, 2014). Through time people attach and give meaning to places because they gain personal relationships within them. This feeling of belonging to a social surrounding is created through one's habitus in relation to one's social surrounding and thus a 'feel for the game' that provides young people with the knowledge to act and think in ways according to their social context (Bourdieu, 1993: 72). Hence, a sense of belonging is not independent from one's habitus, but its interrelation can impact people's behaviour in different ways. Apart from a feeling of knowing what to do, how and when, a sense of belonging can maintain social order to people's disadvantage. Bourdieu (1989) argues that:

'It is this sense of one's place which in interaction, leads people [...] to keep their common place, and the others to "keep their distance," to "maintain their rank", and to "not get familiar" (ibid 1989: 17).

Additionally people with similar systems of dispositions, that is, habitus, tend to inhabit geographical places close to each other and keep their distance from those places that require a different habitus. This can reproduce class distinctions and lead to exclusion of people of other classes who do not 'belong' (cf. Bourdieu, 1989; Bourdieu and Passeron, 1977). Therefore a sense of belonging is not only 
created through a feeling of similarity but also through being aware of dissimilarity and the feeling not to belong.

Reynolds (2013) conducted a study with young black youth in London from a disadvantaged neighbourhood. One of her participants decided to apply for a university with a less good reputation rather than apply to an elite one. Her participant argued that he would not feel at ease studying as the only black student among white students. He rather wanted to stay in familiar structures where he knows what to do when and how. When people feel comfortable and at ease in spaces their habitus corresponds with their social surrounding and they have a sense of belonging in these spaces (May, 2013). In contrast, when the habitus does not correspond with one's social surrounding, people may feel uncomfortable and seek to move socially and spatially to relieve their discomfort (Savage, Bagnall, \& Longhurst, 2005: 9).

Neighbourhoods are places where people develop a sense of belonging and can attach to. They can act as a secure point from where to look out into the world and simultaneously know one's own position in it (Relph, 1976). Tilley (1994) adds that a sense of self bound up with place is a crucial part of identity building. Belonging is then more than a feeling of being comfortable in a place or space, it is a part of one's identity (Miller, 2003: 217). Therefore belonging is a relational concept that plays a role in the construction of one's current and future identity as it is created through relations with significant others in one's social context and how one is recognised by them but also through relations to abstract notions of collectively held values and norms of the society one moves in (May, 2011).

Focusing on young people and their sense of belonging, Cuervo et al. (2014) discuss how the concept of belonging has been used to understand the impact of social change on young people and that it brings the quality of social relationships into focus. They argue that belonging emphasises the importance of relationships between young people and the people in their social context that matter to them such as the ties to family, friends and neighbours. This relationship actually creates the sense of belonging and in turn influences decisions young people make (Cuervo and Wyn, 2014). The young man in Reynolds' (2013) study did feel he belonged to his neighbourhood and the relationships in his social surrounding provided him with a feeling of being at ease there. In contrast, when he was entering the elite university with predominantly white students of a different social class, he felt discomfort, and kept his distance from them, believing that he did not belong to this specific and distinct social surrounding. 
Therefore belonging to a place is linked to being known in a place and having social capital which can act as sources of support and resources for social mobility (Visser, Bolt, \& van Kempen, 2014) and influences young people's identity creation as well as imagined future selves. Being known in an area provides young people with important social capital resources that may also influence their aspirations. Thus while belonging may limit young people's opportunities for social mobility, as in the case of Reynolds' (2013) participant, belonging may also create social opportunities, for example, through contacts that enhance access to resources for social mobility inside and outside one's own neighbourhood.

With respect to aspirations, a sense of belonging therefore may impact young people in different ways. On the one hand it can provide young people with a feeling for the game and being at ease at a certain place and/or space as structures are well known and relationships to significant others are present. On the other hand it can constrain young people's social and spatial mobility through power relations distributed with a sense of belonging, creating a tension between a feeling to belong to a place or space and a feeling of exclusion and being labelled because they belong to particular places and spaces and that signify that they are not the dominant class in a society.

Accordingly young people's future selves and how they act to pursue them are due to an internalised set of principles and attitudes embedded and learned in their social context with its structural constraints and possibilities including the relations young people have within these spaces and their sense of belonging to them. Aspirations of young people are consequently a complex construction in the interrelation of habitus and a sense of belonging and need to be analysed in the young people's particular social context

\subsection{Stigmatisation of neighbourhoods}

Having discussed belonging as a feeling of being at ease in a place and keeping a distance from places where young people feel discomfort, a related influence is stigmatisation because of belonging to a certain neighbourhood. Neighbourhoods are not just places without meaning. They are shaped and given importance to by their inhabitants and their cultures. In cases where neighbourhoods are labelled from the outside as poor, marginalised and dangerous, people in these neighbourhoods suffer from the consequences of this stigmatisation. For example, poor neighbourhoods in Colombia and in most Latin American countries are labelled as dangerous because of their high crime rates and gang cultures (Harding, 2009; Mcllwaine and Moser, 2001). Therefore young people who belong to stigmatised neighbourhoods may not be part of the violent actions in it but suffer from being labelled 
as 'dangerous' by outsiders. Consequences can result in isolation from the wider society where young people are excluded from resources and opportunities for social mobility (Harding, 2009). People from other neighbourhoods, employers and education facilities may be afraid of young people from stigmatised neighbourhoods or look at them in a different way which affects young people and their self-efficacy in acting to enhance their social mobility (Bauder, 2001).

Arthurson (2012) argues that reputation and location can hinder young people from getting a job as the location and reputation can lead to poorer quality teachers to educate the young people and possible employers may discriminate people from stigmatised barrios. Also companies and possible employers may not locate close to a stigmatised neighbourhood and therefore create limitations as transport is expensive and people might not be able to travel to the employment (see section 3.3). Additionally infrastructure is reinforcing this stigma, as physical access can be more difficult and thus difficult to enter for police and other services. This affects young people's physical mobility additionally as described in Section 2.5 below.

\subsection{Geographical location of the neighbourhood}

The geographic location of a neighbourhood can impact young people's physical mobilities and access to resources to enhance their social mobility in several ways. Neighbourhoods that are characterised as disadvantaged provide fewer opportunities for young people to enhance their social mobility. They offer poorer quality education, health care facilities and recreational places, and fewer employment opportunities than better-off neighbourhoods (Musterd and Andersson, 2006). Therefore disadvantaged neighbourhoods have an impact on young people and limit their development of skills and capitals necessary to achieve good employment and social networks to enhance their opportunities (Bauder, 2001). Often young people need to travel to other neighbourhoods in search of education and jobs and the distance may be too far and thus cost too much time and economic capital to realise these travels (Langevang and Gough, 2009). Without even knowing if the investment of these travels pays off, many young people may not be willing to realise these and thus stay rather physically immobile. In contrast, young people from more advantaged neighbourhoods may have the means to travel to resource-richer places outside their own neighbourhood, for reasons such as education and employment. With respect to distance, it is interesting that the decision of the young participant in Reynolds' (2013) study to decide against the elite university was additionally influenced by the distance of the two universities available to him where the elite university was farther away. 
As Van Ham et al. (2012) argue, neighbourhood effects, such as the interrelation of good quality education facilities like elite universities in London and predominantly white neighbourhoods in its surrounding areas, are an important part of individuals' social contexts. This illustrates how spatial segregation and inequalities are produced and reproduced. It is not only that the elite university is of mainly white students, it is also located farther away from the black youth which additionally hinders their access to quality education and separates them from the better-off youth in London. Thus while location is not the only factor that influences the young men's decision not to enter the university, the physical distance and how location divides other intersecting characteristics such as ethnicity and class is a crucial effect that impacts on young people's life chances for the future.

Another example from the global south is illuminated by Langevang and Gough (2009) with their study of young people's mobilities in Accra. In search of upward social mobility the young people have to travel to the city centre of Accra, which is expensive and time consuming. Travel costs are difficult to cover for young people from disadvantaged neighbourhoods in Accra and the costs of travelling to the centre may exceed the earnings they can acquire or they do not have the economic capital to travel there in the first place. Although these young people, in contrast to the young man from London, want to travel to the city centre to try to find work opportunities, they may experience social immobility because they are constrained in their physical mobility through a lack of economic capital to overcome the physical distance. Consequently the location of a neighbourhood demonstrates how the possibility to move to important places is unequally distributed between young people in the city and between places they live in (Lindgren and Lundahl, 2010).

\subsection{Immediate neighbourhood}

While the location of the neighbourhood within the wider city and other important places limits young people's access to opportunities, the immediate neighbourhood may limit young people through access to and quality of local services in the neighbourhood itself (Musterd and Andersson, 2006). For example, the provision of lower quality education in disadvantaged neighbourhoods, in particular in the global south, has been identified as a negative effect as education plays a crucial role in the development and attainment of aspirations and upward social mobility (Allen and Hollingworth, 2013; Crivello, 2011). The quality of teachers and resources such as textbooks at a school facility may influence students' educational outcomes to a high degree. Additionally factors such as violence at schools, bullying and the presence of weapons limits young people from succeeding in school in the same way as young people from better-off neighbourhoods (Pradeilles et al., 2014). Yet when young 
people finish school and apply for higher education or employment, youth from both disadvantaged and advantaged neighbourhoods compete at the higher education level and job market. They do so under unequal conditions though. Bourdieu (1977) argues that the educational system serves to reproduce class hierarchies and thus young people who are disadvantaged in educational opportunities in the compulsory education system start competing afterwards for work and higher education opportunities from different points of departure.

The infrastructure of a neighbourhood, especially in the global south where housing, streets and transportation systems limit physical mobility of young people influences mobilities further. For example, in Cartagena Colombia, where the author conducted fieldwork, poorer neighbourhoods are outside of the city centre and young people are already disadvantaged because of the location of the neighbourhood in relation to other important places. However, in the rainy season, streets are flooded, which contributes to physical immobility. Streets are not paved (apart from main ones) and apart from creating physical immobility this creates additionally standing water and breeding places for dengue mosquitos and thus poses health risks that richer neighbourhoods rarely experience. This illustrates the different boundaries and restrictions young people have to overcome in their everyday life and exemplifies how social navigation can depend on neighbourhood infrastructure whose quality may change with weather conditions.

However, neighbourhood boundaries are not just marked through physical differences. Local habits, behaviour, social activities in disadvantaged neighbourhoods in Cartagena can be observed to be different from those in better-off ones and create additional difficulties for young people's social mobility opportunities. For example, Streicker (1997) describes how disadvantaged neighbourhoods, so called barrios populares, use a certain type of music, 'Champeta', to create audio boundaries between better-off neighbourhoods and barrios populares. These audio boundaries are loud and especially audible during weekends, stretching late into the night. Many people of barrios populares tend to consume alcohol when listening to the music and frequent conflicts on the streets disturb the community. This generates noise pollution, which in itself results in stress, but it also hinders young people from being able to concentrate on their studies in order to obtain the results necessary to enter university and/or the employment market in the future (Sharkey and Faber, 2014). The conflicts related to the times of loud music restrict young people's physical mobility because of the dangers of getting accidently involved when being on the street passing through. 


\subsection{Security issues in neighbourhoods}

Research around issues of security and insecurity such as crime, violence and gang cultures, in neighbourhoods and cities demonstrates their influences on young people's development, mobilities, access to social, economic and cultural resources and thus their aspirations' attainment (Fraser, 2013; Mcllwaine and Moser, 2001; Moser and Mcllwaine, 2004; Winton, 2005).

Although this is a topic much researched in the global south (Winton, 2005), studies show that gang culture is not exclusively present in the global south but also exists in Western countries such as the UK (Fraser, 2013). In this section, however, examples are chosen from the global south and in particular from Latin American cases. In the Latin American context, gang culture creates physical immobility and limits young people's access, in particular when gangs are active such as at night times. Violence, fear of robberies and crime keep young people away from places where these things happen and may restrict their contact with other people and resources necessary to create social capital. Winton (2005) explains how gangs in Guatemala create spatial boundaries by inhabiting places in neighbourhoods such as recreational and public places which leaves young people no other choice than to stay at home. This limits their ability to create social and cultural capital and to follow up on their aspirations. Further, in Colombian and Guatemalan neighbourhoods affected by gangs, the government or lynching groups operate actions to eliminate unwelcome, violent and dangerous people. So called 'social cleansing', the systematic murders of people who are perceived to belong to violent groups or gangs, operates at pronounced hours per day for a certain amount of time (Moser and Mcllwaine, 2004). These operations require that people stay at their home to avoid getting in between those who 'clean' and those who are hunted. For young people this means, apart from being spatially immobile, they may suffer from psychological effects such as fear and stress influencing their performance in areas such as education and employment. The media in Latin American cities affected by violence, murders and gang culture sensationalise these kinds of violence which creates the impression, to a certain extent, that violence is a mundane part of life for its citizens (Winton, 2005). Therefore danger and insecurity affect young people's navigational capacity to create successful future selves as well as creating useful contacts.

While gang culture diminishes social capital opportunities for young people who are not part of gangs as it reduces their physical mobility and thus their possibilities to create and sustain important networks (Langevang and Gough, 2009), fear of gangs can also intensify social capital and produce a form of community social capital as a way of resistance (Mcllwaine and Moser, 2001). In contrast, gangs themselves can be a source of social capital as social capital is produced through membership to 
networks. Gangs can act as those networks and generate access to inclusion and become a source for further capital such as economic and types of cultural capital valued by gangs (Mcllwaine and Moser, 2001). Gangs, therefore, influence not only issues of social exclusion and types of immobility, but they can also act as a source of resources and thus perpetuate gang culture. Spatial boundaries through infrastructural developments and geographical neighbourhood effects may bind young people to spaces and places. Not being able to leave their neighbourhood, for cost and time reasons, or because they do not feel they belong to other spaces and places because of their habitus that does not correspond with outside neighbourhoods, creates a kind of spatial entrapment, and additional place attachment (Fraser, 2013). Being excluded from outside spaces and places to enhance their capital acquisitions, young people join gangs instead which often provides them with possibilities to acquire social and economic capital and be a part of a network that creates a sense of safety and belonging (Fraser, 2013; Mcllwaine and Moser, 2001).

\section{Conclusion}

The chapter started with a discussion of the neo-liberal approach to raising young people's aspirations in order to achieve higher educational and occupational outcomes. This aspirations discourse has been criticised as shifting the balance of the responsibility for achieving upward social mobility onto the young people, making social mobility an individualised obligation (Brown, 2013; Spohrer, 2011). However, aspirations may be developed beyond educational and occupational achievements according to different individual understandings of what is a good life. Accordingly social mobility is more complex: while social mobility is often defined as individuals' upwards and downwards movements in a society's hierarchy, it is not limited to this definition. Living in a safe area, being healthy and living a comfortable life with one's family can be additional understandings of what social mobility consists of. Young people's upward social mobility and the ability to navigate themselves towards them successfully is subsequently not an individualised responsibility easily achievable by just aiming for higher outcomes.

Aspirations and social mobility opportunities are embedded in young people's social context and thus influenced by young people's habitus, knowledge, experiences, acquired capitals and access to resource to enhance their social condition. Additionally young people may need to adjust their aspirations and plans to achieve according to changing circumstances in their social environment and create the ability of what Vigh (2006) calls social navigation, where young people plot their desired 
future from their experiences in the present, being aware of the need for adjustment of their aspirations respectively to the changes in their places and spaces through time.

The aspirations-upward mobility discourse is limited in acknowledging these interrelations. An analysis of young people's aspirations and their navigational capacity to achieve them, therefore needs to include young people's (im)mobilities within and beyond the spaces and places of their everyday life that provide them with the resources necessary to achieve social mobility. Thus, mobility can be understood as a resource itself, and in particular young people's neighbourhoods have been identified as sources for their (im)mobilities and development of the 'right' habitus to attain the 'right' aspirations.

Neighbourhoods and surrounding areas are identified as places and spaces where young people moved in the past, move in the present and from where they look into the future. Mobilities in these places and spaces influence young people's identity and sense of belonging where young people feel they know what to do when and how. They create social capital through family, friends and neighbourhood ties and offer knowledge about how to access resources. However neighbourhoods provide an environment that enables or constrains young people in the access of social mobility opportunities. Especially disadvantaged neighbourhoods separate young people through their location in disadvantaged, often segregated, and sometimes dangerous areas, with lower quality services provided such as education and health care facilities, and less physical access through poorer infrastructure and transportation links compared to better-off neighbourhoods. In many cases disadvantaged neighbourhoods are labelled as poor, dangerous, violent or in other negative ways that result in stigmatisation of young people because they belong to these neighbourhoods. Neighbourhoods that suffer from violence and gang culture contribute to young people's physical immobility, which restricts them in access to resources. In addition, social and geographical isolation can result in perverse social capital and young people may join gangs and criminal groups for a different kind of social mobility to produce economic capital as well as to be part of a network that provides safety and a sense of belonging.

Social mobility therefore is strongly linked to physical mobility. However, it is not necessarily the physical movement itself that provides young people with upward movements in society as illustrated by studies of young people who moved physically but stagnate socially (Gough, 2008; Langevang and Gough, 2009). Neither does having opportunities to move mean that young people will do so if they do not feel comfortable moving to spaces and places that provide them with resources to enhance their social mobility, such as in the case of the black young man who decided against the elite university 
because it did not correspond with his understandings of how to achieve social mobility (Reynolds, 2013).

The aspirations-upward mobility discourse confirms that social mobility is more complex than high achievement in terms of educational and occupational outcomes. What young people want to achieve in the future and how they navigate themselves towards these aspirations is as much dependent on the opportunities provided to them by their social context that intersects with their socioeconomic background, their ethnicity, and other contextual factors as on their own abilities, skills, habitus and capitals. Focusing on mobilities of young people while including these influencing factors and how this interrelation affects young people's experiences and perceptions in ways that determine the future choices they perceive as possible and available to them (Winton, 2005), facilitates an understanding of how young people develop aspirations and can achieve social mobility outcomes. Consequently high aspirations and being able to navigate towards them is not an individualised responsibility but rather a contextual matter. Upward social mobility of young people from disadvantaged neighbourhoods and socioeconomic backgrounds is therefore difficult to attain without providing opportunities to the same extent as they are asked to raise their aspirations and deploy individual investments for their future.

\section{Keywords:}

Aspirations, neighbourhood effects, social and spatial mobility, habitus, social capital, cultural capital, economic capital, belonging

\section{Acknowledgements}

The author is grateful to Dr. Laura Camfield and Dr. Esther Priyadharshini for their valuable comments. This chapter was inspired and resulted from the author's participation at the 4th International Children's Geographies Conference in San Diego in 2015. A special thanks to the Geographies of Children, Youth and Families Research Group of the Royal Geographical Society with IBG for the financial support provided by them, making the participation at his conference possible. 


\section{References}

Allen, K., \& Hollingworth, S. (2013). 'Sticky Subjects' or 'Cosmopolitan Creatives'? Social Class, Place and Urban Young People's Aspirations for Work in the Knowledge Economy. Urban Studies, 50(3), 499-517. doi:10.1177/0042098012468901

Appadurai, A. (2004). The Capacity to Aspire: Culture and the Term of Recognition. In V. Rao \& M. Walton (Eds.), Culture and Public Action. Washington DC: The World Bank.

Arthurson, K. (2012). Social Mix, Reputation and Stigma: Exploring Residents' Perspectives of Neighbourhood Effects. In M. van Ham, D. Manley, N. Bailey, L. Simpson, \& D. Maclennan (Eds.), Neighbourhood Effects Research: New Perspectives. Heidelberg; London; New York: Springer.

Asociación Arte y Cultura, Asociación Mision Mixta, Fundación Grupo Experimental de Alternativas Culturales, \& Asociación de Mujeres Activas por un Futuro Mejor. (2002). Exploring youth and community relations in Cali, Colombia. Environment and Urbanization, 14(2), 149-156. doi:10.1177/095624780201400212

Azevedo, V., \& Bouiilon, C. (2010). Intergenerational Social Mobility in Latin America: A Review of Existing Evidence Revista de Análisis Económico, 25(2), 7-42.

Bauder, H. (2001). Work, young people and neighbourhood representations. Social \& Cultural Geography, 2(4), 461-480. doi:10.1080/14649360120092643

Bourdieu, P. (1977). Outline of a theory of practice: Cambridge : Cambridge University Press, 1977.

Bourdieu, P. (1989). Social Space and Symbolic Power. Sociological Theory, 7(1), 14-25. Retrieved from http://www.jstor.org/stable/202060

Bourdieu, P. (1993). Sociology in Question. London: SAGE.

Bourdieu, P. (2005). Habitus. In J. Hiller \& E. Rooksby (Eds.), Habitus: A Sense of Place (2nd ed., pp. 43 - 49). Aldershot; Burlington: Ashgate.

Bourdieu, P., \& Passeron, J.-C. (1977). Reproduction in Education, Society and Culture. Beverly Hills: Sage Publications Inc.

Brown, G. (2011). Emotional geographies of young people's aspirations for adult life. Children's Geographies, 9(1), 7-22. doi:10.1080/14733285.2011.540435

Brown, G. (2013). The Revolt of Aspirations: Contesting Neoliberal Social Hope. ACME: An International E-Journal for Critical Geographies, 12(3), 419-430. Retrieved from http://search.ebscohost.com/login.aspx?direct=true\&db=a9h\&AN=90516164\&autht ype $=$ sso\&custid=s8993828\&site=eds-live\&scope=site

Crivello, G. (2011). 'Becoming somebody': youth transitions through education and migration in Peru. Journal of Youth Studies, 14(4), 395-411. doi:10.1080/13676261.2010.538043

Cuervo, H., \& Wyn, J. (2014). Reflections on the use of spatial and relational metaphors in youth studies. Journal of Youth Studies, 17(7), 901-915. doi:10.1080/13676261.2013.878796

Fraser, A. (2013). Street habitus: gangs, territorialism and social change in Glasgow. Journal of Youth Studies, 16(8), 970-985. doi:10.1080/13676261.2013.793791 
Gale, T., \& Parker, S. (2015). Calculating student aspiration: Bourdieu, spatiality and the politics of recognition. Cambridge Journal of Education, 45(1), 81-96. doi:10.1080/0305764X.2014.988685

Gough, K. V. (2008). 'Moving Around': The Social and Spatial Mobility of Youth in Lusaka Geografiska Annaler: Series B, Human Geography, 90(3), 243-255. doi:10.1111/j.14680467.2008.290.x

Harding, D. J. (2009). Violence, Older Peers, and the Socialization of Adolescent Boys in Disadvantaged Neighborhoods. American Sociological Review, 74(3), 445-464. Retrieved from http://www.ncbi.nlm.nih.gov/pmc/articles/PMC2776742/

Holloway, S., \& Pimlott-Wilson, H. (2011). The politics of aspiration: neo-liberal education policy, 'low' parental aspirations, and primary school Extended Services in disadvantaged communities. Children's Geographies, 9(1), 79-94. doi:10.1080/14733285.2011.540441

Ibrahim, S. (2011). Poverty, aspirations and wellbeing: afraid to aspire and unable to reach a better life - voices from Egypt, Brooks World Poverty Institute, The University of Manchester.

Kaufmann, V., Bergman, M. M., \& Joye, D. (2004). Motility: mobility as capital. International Journal of Urban and Regional Research, 28(4), 745-756. doi:10.1111/j.03091317.2004.00549.x

Kintrea, K., St Clair, R., \& Houston, M. (2015). Shaped by place? Young people's aspirations in disadvantaged neighbourhoods. Journal of Youth Studies, 1-19. doi:10.1080/13676261.2014.992315

Langevang, T., \& Gough, K. V. (2009). Surviving through movement: the mobility of urban youth in Ghana. Social \& Cultural Geography, 10(7), 741-756. doi:10.1080/14649360903205116

Lindgren, J., \& Lundahl, L. (2010). Mobilities of Youth: Social and Spatial Trajectories in a Segregated Sweden. European Educational Research Journal, 9(2), 192-207. doi:10.2304/eerj.2010.9.2.192

Massey, D. (1998). The Spatial Construction of Youth Cultures. In T. Skelton \& G. Valentine (Eds.), Cool Places: Geographies of youth cultures. London; New York: Routledge.

May, V. (2011). Self, Belonging and Social Change. Sociology, 45(3), 363-378. doi:10.1177/0038038511399624

May, V. (2013). Connecting Self to Society: Belonging in a Changing World. New York: Palgrave Macmillan.

Mcllwaine, C., \& Moser, C. O. N. (2001). Violence and social capital in urban poor communities: perspectives from Colombia and Guatemala. Journal of International Development, 13(7), 965-984. doi:10.1002/jid.815

Miller, L. (2003). Belonging to country - a philosophical anthropology. Journal of Australian Studies, 27(76), 215-223. doi:10.1080/14443050309387839

Moser, C. O. N., \& Mcllwaine, C. (2004). Encounters with violence in Latin America : urban poor perceptions from Colombia and Guatemala: New York, N.Y. ; London : Routledge, 2004.

Musterd, S., \& Andersson, R. (2006). Employment, Social Mobility and Neighbourhood Effects: The Case of Sweden. International Journal of Urban and Regional Research, 30(1), 120-140. doi:10.1111/j.1468-2427.2006.00640.x 
Perlman, J. E. (2006). The Metamorphosis of Marginality: Four Generations in the Favelas of Rio de Janeiro. The ANNALS of the American Academy of Political and Social Science, 606(1), 154177. doi:10.1177/0002716206288826

Pradeilles, R., Rousham, E. K., Norris, S. A., \& Griffiths, P. L. (2014). Urban South African Adolescents' Perceptions of Their Neighborhood Socio-Economic Environments: The Birth to Twenty Plus Cohort Study. Children, Youth and Environments, 24(3), 173-200. doi:10.7721/chilyoutenvi.24.3.0173

Prince, D. (2013). What about place? Considering the role of physical environment on youth imagining of future possible selves. Journal of Youth Studies, 17(6), 697-716. doi:10.1080/13676261.2013.836591

Ray, D. (2006). Aspirations, Poverty, and Economic Change. In V. Banerjee, R. Bénabou, \& D. Mookherjee (Eds.), Understanding Poverty. Oxford: Oxford University Press.

Relph, E. C. (1976). Place and placelessness London: Pion.

Reynolds, T. (2013). 'Them and Us': 'Black Neighbourhoods' as a Social Capital Resource among Black Youths Living in Inner-city London. Urban Studies, 50(3), 484-498. doi:10.1177/0042098012468892

Savage, M., Bagnall, G., \& Longhurst, B. (2005). Globalization and belonging: London : Sage, 2005.

Sharkey, P., \& Faber, J. W. (2014). Where, When, Why, and For Whom Do Residential Contexts Matter? Moving Away from the Dichotomous Understanding of Neighborhood Effects. Annual Review of Sociology, 40(1), 559-579. doi:doi:10.1146/annurev-soc-071913-043350

Sheller, M., \& Urry, J. (2006). The new mobilities paradigm. Environment and Planning A, 38(2), 207-226. Retrieved from http://www.envplan.com/abstract.cgi?id=a37268

Skelton, T. (2013). Young People's Urban Im/Mobilities: Relationality and Identity Formation. Urban Studies, 50(3), 467-483. doi:10.1177/0042098012468893

Skelton, T., \& Gough, K. V. (2013). Introduction: Young People's Im/Mobile Urban Geographies. Urban Studies, 50(3), 455-466. doi:10.1177/0042098012468900

Small, M. L., \& Feldman, J. (2012). Ethnographic Evidence, Heterogeneity, and Neighbourhood Effects After Moving to Opportunity. In M. van Ham, D. Manley, N. Bailey, L. Simpson, \& D. Maclennan (Eds.), Neighbourhood Effects Research: New Perspectives. Heidelberg; London; New York: Springer.

Spohrer, K. (2011). Deconstructing 'Aspiration': UK Policy Debates and European Policy Trends. European Educational Research Journal, 10(1), 53-63. doi:10.2304/eerj.2011.10.1.53

Streicker, J. (1997). Spatial Reconfigurations, Imagined Geographies, and Social Conflicts in Cartagena, Colombia. Cultural Anthropology, 12(1), 109-128. doi:10.1525/can.1997.12.1.109

Tilley, C. Y. (1994). A phenomenology of landscape: places, paths, and monuments. Oxford: Berg.

van Ham, M., Manley, D., Bailey, N., Simpson, L., \& Maclennan, D. (2012). Neighbourhood Effects Research: New Perspectives. Heidelberg; London; New York: Springer.

Vigh, H. E. (2006). Navigating Terrains of War: Youth and Soldiering in Guinea-Bissau. New York; Oxford: Berghahn Books. 
Visser, K., Bolt, G., \& van Kempen, R. (2014). 'Come and live here and you'll experience it': youths talk about their deprived neighbourhood. Journal of Youth Studies, 1-17. doi:10.1080/13676261.2014.933196

Wilson, W. J. (1987). The truly disadvantaged : the inner city, the underclass, and public policy: Chicago ; London : University of Chicago Press, 1987.

Winton, A. (2005). Youth, gangs and violence: Analysing the social and spatial mobility of young people in Guatemala City. Children's Geographies, 3(2), 167-184.

doi:10.1080/14733280500161537 